\title{
Educação à distância no Brasil: desafios e perspectivas no início do terceiro milênio
}

\author{
Rosa Maria Cardoso Dalla Costa* \\ Armando João Dalla Costa**
}

RESUMO: O presente texto faz um panorama do Sistema Brasileiro de Educação à Distância, que segundo dados do MEC - Ministério da Educação e Cultura - em 2007 apresentava o número de 973 mil alunos e 257 instituições credenciadas, movimentando 1,5 milhões de reais. A partir de um breve histórico do ensino a distância no Brasil, o texto apresenta uma análise das implicações dessa rápida expansão ocorrida principalmente nos últimos cinco anos, tais como a qualidade do ensino ministrado, a democratização do acesso à educação num país com dimensões geográficas continentais, o desafio da formação dos professores, a proposta didático-metodológica em questão e, finalmente, o embate entre o público e privado neste cenário, que apesar de se inserir no movimento internacional de globalização, tem peculiaridades cultural e historicamente determinadas. Todo esse processo de expansão da educação a distância no contexto brasileiro é analisado sob o enfoque teórico da comunicação-educação, que situado na interface entre as duas ciências procura explicar o fenômeno da inserção das novas tecnologias no ambiente escolar.

Palavras-chave: Educação à distância. Comunicação-educação. Novas tecnologias. Ensino. Educação brasileira.

\section{UM CENÁRIO DE NÚMEROS GIGANTESCOS}

Entre 2004 e 2007, segundo dados publicados na revista Exame ${ }^{33}$, o número de alunos matriculados em cursos técnicos, de graduação e pós-graduação no segmento de educação à distância cresceu $214 \%$ e chegou a quase um milhão de estudantes. Segundo a revista "hoje, 7\% dos 5 milhões de universitários brasileiros estudam longe das salas de aula, participando de cursos que vão de enfermagem a pedagogia, de administração de empresas a turismo."

Esses números se inserem no contexto mais amplo da Educação Brasileira, em especial no que diz respeito ao ensino superior, que passou por um gigantesco processo de

\footnotetext{
* Pós-Doutora na Maison des Sciences de l'Homme, Paris Nord. Doutora pela Université de Vincennes, Paris VIII. Professora do Departamento de Comunicação Social e do Programa de Pós Graduação em Educação da UFPR. Diretora cultural da Intercom - Sociedade Brasileira de Estudos Interdisciplinares da Comunicação. Endereço eletrônico: rmcdcosta@ufpr.br.

** Pós-Doutor pela Université de Picardie Jules Verne, Amiens, França. Doutor pela Université Paris III (Sorbonne Nouvelle). Professor do Departamento de Economia e do Programa de Pós-Graduação em Desenvolvimento Econômico da UFPR. Coordenador do Núcleo de Pesquisa em Economia Empresarial (www.empresas.ufpr.br). Endereço eletrônico: ajdcosta@ufpr.br.

33 AMORIM, Lucas. Os alunos estão cada vez mais longe. In: Revista EXAME, edição 938, Ano 43, nº 411 de março de 2009, p. 100-102.
} 
expansão e de privatização, a partir dos anos de 1990. Segundo dados do Censo de Educação Superior, realizado em 2007, e divulgado no site do Inep (Instituto Nacional de Estudos e Pesquisas Educacionais Anísio Teixeira ${ }^{34}$ ) o Brasil tinha naquele ano 2.281 instituições de ensino superior, 23.488 cursos e 4.880 .381 de estudantes. Quando esses dados são confrontados com os de educação à distância mostram que um quinto dos alunos do ensino superior brasileiro já utiliza essa nova modalidade de ensino.

O mesmo censo aponta que existem 97 instituições que oferecem cursos de graduação à distância. Comparados ao ano de 2006, constata-se a criação de 59 novos cursos, o que representa um aumento de $16,9 \%$ em relação aos cursos e um aumento de 89,4\% em relação ao número de vagas oferecidas, ou seja, 727.520 a mais que o ano anterior. De 2003 a 2007 houve uma variação de 6.314\% no número de vagas ofertadas para ensino superior à distância no território brasileiro. No Sistema de Ensino Brasileiro - considerando-se outros níveis além do superior - são 257 instituições credenciadas pelo MEC e 973 mil alunos, que movimentaram 1,5 milhões de reais em 2007.

Num país com aproximadamente 8,5 milhões de quilômetros quadrados e 185 milhões de habitantes, esse crescimento do ensino à distância aponta antes de qualquer coisa, uma maior democratização do acesso ao ensino para aqueles que vivem em cidades mais distantes. Uma análise aprofundada dessa expansão mostra, porém, que da mesma forma como ocorreu com o ensino superior, a educação à distância se transformou num mercado promissor para os grupos privados nacionais e até internacionais de ensino, provocando um crescimento que nem sempre vem acompanhado de qualidade. O dilema público-privado do ensino superior, cujos dados também do Inep, informam o número de 1.240.968 alunos no ensino superior público e 3.639.413 alunos no privado, evidenciam a tendência do nicho de crescimento da educação à distância no cenário brasileiro. Num processo de democratização às avessas é o ensino privado que acaba proporcionando às classes menos favorecidas o acesso à educação, em especial nos níveis médio, técnico e superior, enquanto as classes com maior poder aquisitivo, que geralmente frequentam o ensino fundamental em instituições particulares obtêm com maior facilidade um lugar no ensino público superior, reconhecidamente de melhor qualidade.

Citando dados da consultoria Hoper a revista Exame relata que um curso de graduação à distância custa em média 168 reais por mês, enquanto num curso tradicional e

${ }^{34}$ Disponível em: HTTP:/ /www.inep.gov.br. Acesso em 20/03/2009.

80 
presencial o preço do mesmo curso não sai por menos do que 457 reais. ${ }^{35}$ Essa diferença de preço atrai diferentes tipos de público, desde aqueles que habitam em cidades mais distantes que não oferecem curso superior em áreas diversificadas até pessoas mais velhas, que não puderam estudar e querem agora fazê-lo sem alterar ou sobrecarregar sua jornada de trabalho. Assim, apesar dos esforços do governo no sentido de ampliar os programas de educação à distância nas universidades públicas brasileiras, é mesmo no setor privado que o segmento tende a crescer pelo menos 20\% ao ano, segundo o presidente da Associação Brasileira de Educação à Distância, citado pela revista. Apenas as cinco maiores instituições particulares de ensino à distância no Brasil detêm cerca de 50\% do total de alunos deste segmento.

Um crescimento assim expressivo e rápido, confrontando os princípios do ensino público com o senso de oportunidade do setor privado, tem características peculiares como será descrito a seguir.

\section{HISTÓRIA DA EAD NO BRASIL}

Um breve relato histórico da EAD no Brasil serve de orientação para uma análise de suas principais características. A história da educação à distância de uma maneira geral sempre esteve atrelada à história do desenvolvimento de novas tecnologias, em especial àquelas voltadas para a transmissão de mensagens à distância. No Brasil, cada nova tecnologia representa uma esperança de aumento de acesso à educação e diminuição das diferenças de desenvolvimento regional ou ainda das diferenças entre o urbano e o rural.

Assim, a primeira modalidade de ensino não presencial no sistema brasileiro de educação teve início em $1904^{36}$, através do ensino por correspondência, promovido por instituições privadas que passaram a ofertar cursos técnicos sem exigir escolarização anterior. Braga e Calazans (2001, p. 10) afirmam que "a cada nova invenção tecnológica, a sociedade atribui aos processos comunicacionais, desenvolvidos em torno da invenção, uma expectativa educacional". No Brasil, essa expectativa se mostrou mais significativa a partir da invenção do rádio e do interesse do empresário Roquete Pinto em utilizá-lo para que a cultura e a educação chegassem finalmente, de forma democrática, a todos os lares brasileiros (SOARES, 1999, p. 20).

Foi, portanto, com o rádio e o espírito do visionário Roquete Pinto, que a educação à distância começou a se popularizar, principalmente por possibilitar o acesso à educação

\footnotetext{
${ }^{35}$ Em 23/03/2009 um dólar correspondia a R \$2,265 - dólar comercial.

${ }^{36}$ Dados disponíveis em http://ccuap.incubadora.fapesp.br/potal/coletivo/1-historico-da-ead.
} 
àquela parcela da população que, alijada dos bancos escolares, sequer sabia ler. A criação da Rádio Sociedade do Rio de Janeiro em 1923, do grupo liderado por Henrique Morize e o próprio Roquete Pinto foi um marco neste processo. Em 1936 essa rádio foi doada ao então Ministério da Educação e Saúde. Logo em seguida, em 1939, é criado o Instituto Monitor e em 1941, o Instituto Universal Brasileiro, responsável pela formação técnico-profissional por correspondência de várias gerações de jovens e adultos.

Depois, na década de 1960, “as autoridades brasileiras acreditavam na idéia da televisão como instrumento educacional, capaz até mesmo de substituir a escola tradicional e seus professores" (CAPPARELLI; LIMA, 2004, p.125).

Inicia-se, assim, uma ação sistematizada do governo federal em EAD, através de um contrato entre o MEC (Ministério da Educação e Cultura) e a CNBB (Conferência Nacional dos Bispos do Brasil) que promove uma expansão do sistema de escolas radiofônicas aos estados do Nordeste e que resulta na criação do MEB - Movimento de Educação de Base.

É também nesta década que a televisão se expande no cenário brasileiro, em parte incentivada pelo regime militar em vigor entre 1964 e 1985. Segundo Renato Ortiz, é durante esse regime de autoritarismo que são criadas várias entidades estatais que fiscalizam e organizam os meios de comunicação de uma maneira geral. É criado o Sistema Nacional de Radiofusão, em 1964 e, em 1965, têm início os trabalhos da Comissão para Estudos e Planejamento da Radiofusão educativa. De 1966 a 1974 são criadas oito emissoras de televisão educativa nos estados de Pernambuco, Maranhão e Rio Grande do Norte, na região Nordeste; em São Paulo, Rio de Janeiro e Espírito Santo na região Sudeste; no Amazonas, na região Norte e no Rio Grande do Sul, na região Sul.

Também no setor de comunicações há uma forte dicotomia entre o público e o privado. De um lado, governos estaduais criam projetos de televisão e rádios educativas, como o do estado de São Paulo, que cria a Fundação Padre Anchieta para promover atividades educativas e culturais através do rádio e da televisão. De outro, o setor privado investe fortemente nos meios de comunicação que passam a atuar como um norteador de comportamento para as grandes migrações de brasileiros que se movimentam do campo para os principais centros urbanos do país, em busca de uma vida melhor.

É neste contexto que a Rede Globo, emissora do grupo Roberto Marinho, se transforma na principal rede de televisão privada do país, desenvolvendo o chamado "padrão Globo de qualidade", que lhe confere mais de 50\% da audiência nacional. 
A aliança entre a Rede Globo e o Regime Militar trouxe frutos significativos para a relação comunicação-educação, principalmente no que diz respeito à EAD. Em 1977, Roberto Marinho, presidente das Organizações Globo, cria a Fundação Roberto Marinho, uma instituição de caráter privado sem fins lucrativos, que passa a ter abatimento de impostos e a captar recursos do governo federal e do mercado, através da venda de fascículos, para desenvolver projetos de educação à distância. O principal deles é o Telecurso $1^{\circ}$ e $2^{\circ}$ grau, cujo objetivo é o de prover conhecimento baseado no currículo do ensino fundamental e médio por meio da televisão. Segundo Castro (citado por BRITTOS; BOLÃNO, 2005, p. 256)

pesquisa realizada em 2004 (27 anos depois) com o público do Telecurso 2000 revelou que 7 milhões de brasileiros assistem semanalmente ao programa. Dessa audiência, cerca de 400.000 pessoas planejam conseguir o diploma de $1^{\circ}$ e $2^{\circ}$ graus. Mas a grande maioria dos telespectadores procura o chamado edutainment (educação com entretenimento) ou seja, uma forma divertida de se educar.

O telecurso começou a ser transmitido também pelo rádio, através de uma adequação do Projeto Minerva, desenvolvido pelo governo militar desde 1970. "Como o rádio atingia localidades não cobertas pela televisão e como não existiam bancas de jornal para venda de fascículos, foi criado um sistema de mala direta para atender pelo correio os alunos que acompanhavam o telecurso pelo rádio", explica a autora.

Ao mesmo tempo, algumas medidas do governo federal tentam exigir um caráter mais educativo desses meios de comunicação em expansão, como a Portaria 408 que obriga as emissoras de rádio e televisão a destinarem cinco horas de programação semanal e pelo menos trinta minutos diários, de segunda a sexta feira e 75 minutos aos sábados e domingos para a transmissão de cursos do Projeto Minerva, de Capacitação Ginasial e Madureza, produzidos pela Feplam e pela Fundação Padre Anchieta.

A partir daí vários outros projetos, dentre os quais destacamos o Projeto Saci, o Prontel - Programa Nacional de Teleducação- e a ABT - Associação Brasileira de Teleeducação - são criados com o objetivo de suprir a falta de escolas nas regiões mais distantes e promover o acesso à educação para as populações menos favorecidas.

Já o uso do computador na escola teve início, segundo Brito e Purificação (2003, p. 47) na década de 1970, inicialmente em universidades e, posteriormente chegando às escolas de nível fundamental e médio, na década de 1990. 
Nas décadas seguintes, há uma forte expansão do ensino superior no cenário brasileiro, a criação de novos cursos e de instituições privadas, que passam a oferecer cursos supletivos à distância, com aulas via satélite complementadas por kits de materiais impressos. A universidade virtual, compreendida como ensino superior a distância com uso de Tecnologias de Comunicação e Informação (TIC), surgiu no Brasil na segunda metade da década de 1990.

As universidades brasileiras passaram a se dedicar à pesquisa e à oferta de cursos superiores à distância e ao uso de novas tecnologias nesse processo a partir de 1994, com a expansão da Internet nas Instituições de Ensino Superior (IES) e com a publicação da Lei de Diretrizes e Bases para a Educação Nacional (LDB), em dezembro de 1996, que oficializou a EAD como modalidade válida e equivalente para todos os níveis de ensino. Em 1997, universidades e centros de pesquisa passaram a gerar ambientes virtuais de aprendizagem, iniciando a oferta de cursos de pós-graduação latu sensu via internet, demarcando assim, entre 1996 e 1997, o nascimento da universidade virtual no Brasil.

Brito e Purificação (2008, p.72) fazem um levantamento histórico das principais ações da política de informática educativa no Brasil, que acaba repercutindo na EAD. Neste quadro destacam a criação da SEI - Secretaria Especial de Informática - em 1979, o I Seminário Nacional de Informática na Educação, realizado em 1981 em Brasília, a criação do projeto Educom (Educação com computadores), em 1983, que foi a primeira ação oficial e concreta para levar os computadores até as escolas públicas.

Entre 1999 e 2001 universidades virtuais formaram redes de cooperação acadêmica, tecnológica ou comercial entre instituições brasileiras, e entre estas e organizações internacionais. Neste período, passaram a ser organizados consórcios por afinidade regional, consórcios temáticos e redes de instituições públicas, privadas e confessionais.

Do ponto de vista das políticas públicas, merece destaque neste cenário a criação do Proinfo, projeto que visava à formação de NTEs (Núcleos de Tecnologias Educacionais) em todos os estados do país (BRITO; PURIFICAÇÃO, 2008, p. 73). 


\section{REGULAMENTAÇÃO DA EAD NO BRASIL}

Segundo Bernardo ${ }^{37}$ a Educação à Distância no Brasil foi normatizada pela Lei de Diretrizes e Bases da Educação Nacional (Dezembro de 1996), em Fevereiro de 1998.

De acordo com o Art. $2^{\circ}$ do Decreto n. ${ }^{\circ} 2494 / 98$,

os cursos a distância que conferem certificado ou diploma de conclusão do ensino fundamental para jovens e adultos, do ensino médio, da educação profissional e de graduação serão oferecidos por instituições públicas ou privadas especificamente credenciadas para esse fim (...).

Conforme essa regulamentação, as propostas de cursos nestes níveis devem ser encaminhadas ao órgão do sistema municipal ou estadual responsável pelo credenciamento de instituições e autorização de cursos - a menos que se trate de instituição vinculada ao sistema federal de ensino, quando, então, o credenciamento deverá ser feito pelo Ministério da Educação.

Os cursos de graduação e educação profissional em nível tecnológico, a instituição interessada deve credenciar-se junto ao MEC, solicitando, para isto, a autorização para cada curso que pretenda oferecer.

Os programas de mestrado e doutorado na modalidade à distância, no Brasil, ainda são objetos de regulamentação específica. Os cursos de pós-graduação lato sensu, chamados de "especialização", até o início dos anos 1990 eram considerados livres, ou seja, independentes de autorização para funcionamento por parte do MEC. Porém, o Parecer n. ${ }^{\circ}$ 908/98 (aprovado em 02/12/98) e a Resolução no 3 (de 05/10/99) da Câmara de Educação Superior do Conselho Nacional de Educação, que fixam condições de validade dos certificados de cursos presenciais de especialização, tornaram necessária a regulamentação de tais cursos na modalidade à distância. Amorin afirma que a rápida expansão do setor nos últimos cinco anos "fez com que o Ministério da Educação apertasse o cerco às instituições". Uma das medidas mais drásticas foi tomada pelo governo em 2007, quando se passou a exigir que as “instituições instalem computadores e bibliotecas nos chamados pólos de ensino - estruturas com professores para tirar dúvidas nas cidades em que há alunos matriculados em cursos à distância”.

37 BERNARDO, Viviane. Disponível em http://virtual.epm.br/material/tis/enf/apostila.htm. Acesso em $21 / 03 / 2009$. 


\section{CARACTERÍSTICAS DA EAD NO BRASIL}

No II Seminário de Educação à Distância, realizado em Brasília, no ano de 1991, presidente da ABT - Associação Brasileira de Tecnologia Educacional - apontou que o Brasil estava diante do "enorme desafio de construir um sistema educacional, em que se recupere o equilíbrio do trinômio universalização, democratização e excelência”. Segundo apontou em sua palestra, para atingir esse equilíbrio a educação à distância no Brasil deveria se desvencilhar de três de seus principais vícios. O primeiro deles é o de compreender a educação a distância como um expediente barato para atingir grandes contingentes de estudantes. O segundo, o de compreendê-la como um expediente alternativo par suprir a falta de escolarização e, finalmente, o terceiro, o vício de ver a educação à distância como uma forma de obviar a importância da função docente (SALVADOR citado por NISKIER, 1992, p. 224).

A realidade mostra que esse cenário ideal de EAD ainda está longe de ser alcançado. Segundo Brito e Purificação (2008) o uso de tecnologia educacional é marcado por uma série de problemas que podem ser resumidos nos seguintes pontos: disparidade de recursos entre escolas públicas e privadas; falta de preparação de professores e funcionários para a utilização das TICs na escola; falta de políticas públicas que articulem esse uso com as diretrizes curriculares implementadas e representação dos alunos e seus familiares em relação ao papel da escola e das TICs na sociedade.

No que diz respeito à disparidade entre escolas públicas e privadas, Brito e Purificação (2008, p. 48) afirmam que

as escolas particulares ostentam um grau significativo de informatização, muitas vezes escolhendo um modelo prático e rápido de montagem destes laboratórios: feito o investimento em equipamentos, contrata-se uma assessoria especializada para cuidar do laboratório e não se pensa mais nisso.

Já as públicas, vão se informatizando mais lentamente, muitas vezes através de recursos obtidos junto à própria população organizada em Associações de Pais e Mestres (APM), ou via parcerias com empresas e outros segmentos da sociedade.

As iniciativas dos governos federais, estaduais e municipais, na maioria das vezes atendem mais aos interesses das empresas fornecedoras dos produtos do que propriamente as escolas (OLIVEIRA, 2001). Os professores, por sua vez, já sobrecarregados por suas longas jornadas de trabalho e seus baixos salários, têm ainda a incumbência de aprender a lidar com as novas tecnologias, seja para atender às exigências do Estado, seja para se adequarem às 
novas linguagens e comportamentos de seus alunos. Sua formação ainda é tratada com discursos vazios e não dão conta de prepará-los para os novos desafios que a escola lhes propõe. Os alunos e seus familiares, por sua vez, apesar de estarem cada vez mais inseridos na sociedade tecnológica, ainda têm uma representação da escola, como local de aprendizado rigoroso e estruturado, em oposição às características dinâmicas e de entretenimento dos meios e das Novas Tecnologias da Informação e da Comunicação.

Em relação aos conteúdos, o que se observa é, na maioria dos casos, uma transposição dos modelos utilizados nos materiais didáticos profissionais. Segundo Brito e Purificação (2003, p. 56) o mercado brasileiro já possui um grande número de softwares denominados educacionais, mas poucos realmente atingem um verdadeiro objetivo no processo ensino-aprendizagem, ou seja, o de propiciar condições para que o aluno aprenda a buscar informações e saiba usá-las ao invés de recebê-las e memorizá-las, esquecendo-as rapidamente. As autoras apresentam uma categorização dos softwares utilizados na educação: exercícios e prática, tutoriais, tutores inteligentes, simuladores e jogos educativos, além das linguagens de programação e ferramentas. Essas categorias de softwares podem ser utilizadas de forma simultânea e articulada, desde que devidamente planejada.

Há ainda a questão cultural. De que forma as TICs modificam a trama cultural das escolas brasileiras, já enormemente diversificada pela imensa área geográfica do país e todas as variáveis dela derivada? Para Jacquinot Delaunay (2008, no prelo) a tradição do ensino (ao menos no Ocidente) repousa sobre a concepção do conhecimento concebido como acumulação, adição de saberes, "sobre a idéia de construir um edifício partindo do solo, partindo do zero e de começar a juntar peça por peça para construir". As tecnologias da informação e da comunicação obrigam-nos a mudar essa perspectiva, a não mais limitar o olhar à aparência do mundo, e o conhecimento aos traços da informação: os novos modos de ver e de pensar o real e as novas modalidades de comunicação aparecem e em consequência, aparecem novos modos de acesso e de apropriação de saberes. A elaboração dos softwwares educativos deve considerar esse novo processo de comunicação na elaboração de seus produtos, tanto do ponto de vista da forma como do conteúdo e da cultura. Como ocorreu historicamente com o livro impresso, o rádio e a televisão, a sociedade levou um tempo para aprender a nova linguagem e as especificidades de cada novo meio de comunicação. O desafio que se coloca, do ponto de vista dos conteúdos, é o de se evitar que os softwares educativos sejam "o velho fantasiado de novo". 
Dessa maneira, apesar de a escola ainda ser um dos locais privilegiados de acesso às Novas Tecnologias, esse acesso ainda não foi capaz de transformar o ensino, adequando-o às novas linguagens e novos processos comunicacionais característicos desses novos meios. Cabe questionar então se a EAD utiliza a tecnologia como um catalisador responsável pela mudança no paradigma educacional. Dentro desse paradigma, a promoção da aprendizagem é prioritária, visando o processo de construção do conhecimento, habilidades e informações pelo próprio aluno.

Santos (2003, p.36) ao analisar as novas práticas curriculares de educação à distância afirma que "muito mais do que apenas dinamizar e promover nova materialização da informação, a tecnologia digital permite a interconexão de sujeitos, de espaços e/ou cenários de aprendizagem, exigindo dos mesmos novas ações curriculares, ações em rede".

Segundo a autora, o centro do processo do ensino a distância é o material ou recurso didático. Estes normalmente se configuram como pacotes prontos, que se apresentam de forma linear seqüenciada e com pouca multiplicidade.

O Anuário Brasileiro de Educação à Distância publicado pela ABED - Associação Brasileira de Educação a Distância - comprova o que diz Santos ao apontar que, apesar do material impresso ser amplamente utilizado, o apoio ao aluno à distância ocorre primordialmente com o uso de tecnologias mais recentes ${ }^{38}$.

A prova escrita presencial ainda é a forma de avaliação mais utilizada pelas instituições de EAD, sendo utilizada por $64,3 \%$ delas. O e-mail é o apoio tutorial mais comum nas escolas de EAD, sendo usado por 86,75\% delas. Em seguida vem o telefone (82,7\%), o professor online $(78,6 \%)$ e o professor presencial $(70,4 \%)$. A mídia mais utilizada para as aulas de EAD é a impressa (84,7\% das escolas a utilizam). Em seguida, vem o e-learning $(61,2 \%)$ e o CD- ROM (42,9\%).

Para Santos (2003, p. 32) faz-se necessário, diante do paradoxo entre a natureza do ciberespaço, da rede e as produções lineares encontradas no mesmo, "discutir novas dimensões de comunicação para que novas ações sejam materializadas, sobretudo no campo do currículo e da educação". Completando sua análise, ela afirma que apesar de todo o aparato tecnológico a educação continua sendo "uma obrigação chata e burocrática." Isso porque o velho modelo da educação se repete: o professor/autor elabora conteúdos para materiais didáticos de $\mathrm{EAD}$, o professor tutor auxilia autores e instrutores, e principalmente

38 Disponível em http://ccuap.incubadora.fapesp.br/portal/coletivo/1-historico-da-ead/. Acesso em 18/03/2009. 
alunos, a serem bem sucedidos no processo de ensino-aprendizagem, mas não têm permissão para mudar conteúdos e linhas pedagógicas propostas pelos autores/coordenadores dos cursos.

\section{CONCLUSÃO}

A proposta deste texto é a de analisar as mudanças ocorridas no sistema de Educação a Distância no Brasil, dentro do contexto da nova conjuntura mundial no início do terceiro milênio. A análise aqui proposta evidencia que no Brasil a EAD passou nos últimos anos por um intenso processo de privatização e se tornou um investimento altamente lucrativo para empresas nacionais e internacionais, que começam a se instalar no país.

Como ocorreu com o ensino de uma maneira geral, essa privatização acelerada pelas oportunidades de mercado nem sempre está sintonizada com as políticas públicas de educação, provocando resultados muito mais quantitativos do que qualitativos. O rápido desenvolvimento de programas e cursos de educação à distância no Brasil provocou uma série de experiências bem sucedidas, mas isoladas, como afirmou Antonio Ibañez (1991) ao apontar para a necessidade urgente de se investir na formação de profissionais. Segundo ele, para isso são necessárias

... mudanças estruturais que garantam poder econômico à família, para que possa permitir que as crianças em idade escolar frequentem a escola, com isso aumentando o volume de estudantes que saem do ensino fundamental e passam para o ensino médio; aumenta-se então, o número de estudantes neste estágio, permitindo que haja um número maior de alunos, provocando o aumento do número de vagas nas Universidades (IBAÑEZ, 1991, citado por NISKIER, 1992, p. 234).

Concluindo, o autor afirma que é necessária uma determinação política para que a Educação à Distância seja implementada como solução para se educar em quantidade e qualidade num país como o Brasil.

Para atingir esse objetivo, entretanto, além de solucionar suas questões institucionais e políticas internas, o Brasil deve enfrentar o desafio que se coloca a todos os demais países inseridos no processo de globalização que é o de adequar os sistemas de ensino às características da sociedade tecnológica.

Neste esboço dos principais entraves da relação entre comunicação, novas tecnologias e escola, pode-se perceber a necessidade, principalmente para os países e continentes cujo acesso a elas ainda é desigual e precário, de se estabelecer estratégias de ação 
para que como diz Martin-Barbero (2007, p. 18), “a revolução digital sirva a uma revolução que faça possível o reconhecimento do verdadeiro valor e da riqueza que compreende a diversidade cultural".

A principal dessas ações, segundo o autor, é a de um projeto de alfabetização virtual, nos moldes como Paulo Freire pensou a alfabetização 'libertadora' de adultos nos anos 1960. Essa alfabetização deve ter como principal peculiaridade a interatividade:

\begin{abstract}
... esto es en la que el aprendizaje se realiza mediante el proceso mismo de uso de la tecnologia. Un uso que puede y, en ciertos casos, debrá ser orientado, pero que en ningun caso puede ser suplido por meros conocimientos convencionales. (...) Navegar es tambien leer pero no de izquierda a derecha ni de arriba abajo, ni siguiendo la secuencia de las páginas, sino atravesando textos, imágenes y sonidos, conectados entre si por muy diversos modos de articulación, simulación, sonidos, modelando el juego. Modos esos de articulación virtual cuyas habilidades hacen parte indispensable de los saberes que requiere cada dia com mayor frecuencia el mundo laboral y cultural de hoy. (MARTIN-BARBERO, 2007, p. 19).
\end{abstract}

Para dar conta desse desafio, que não é apenas latino americano, é preciso investir cada vez mais na inter-relação entre comunicação e educação, enquanto campo epistemológico e teórico. Uma reflexão que adentre no debate metodológico propondo, como Orofino (2005, p. 150) uma discussão sustentada por um paradigma educacional, problematizador, dialógico, crítico e de complexidade. Nele, todas as dimensões das TICs devem ser contempladas: da sua inserção no universo macroeconômico político e social, às especificidades de sua linguagem e à subjetividade de cada indivíduo que a utiliza e que lhe dá sentido final, a partir das mediações as quais está submetido.

A proposta dessa inter-relação comunicação-educação, embora não tenha o caráter maniqueísta dos estudos dos anos 1960 e 1970 no continente latino americano, pode desencadear uma nova compreensão crítica da realidade, que desafie ainda mais a crise das ideologias dominantes (Orofino, 2005, p. 151). O que não significa, de maneira alguma, creditar às Novas Tecnologias a aura salvadora de todos os problemas sociais do continente. O que se propõe é um processo no qual a inserção das TICs e seus novos conteúdos nestes países ocorra de uma maneira democrática e acessível a todos de maneira igualitária. Esse processo, entretanto, como o do desenvolvimento das Novas Tecnologias da Informação e da Comunicação, é irreversível e a escola não pode mais escamoteá-lo.

No que diz respeito à educação à distância, vale ressaltar que as políticas públicas devem fiscalizar rigorosamente tanto o avanço das empresas privadas nacionais e internacionais do setor, como das entidades públicas que oferecem esse tipo de atividade.

90 
Além disso, as políticas públicas precisam ter suas próprias ações a fim de que esse novo sistema educacional - possibilitado pelo avanço tecnológico - recupere o verdadeiro sentido da palavra educação, que é o de possibilitar ao educandos as condições necessárias para compreender o mundo em que vive e atuar nele com autonomia e criticidade.

\section{REFERÊNCIAS}

AMORIM, Lucas. Os alunos estão cada vez mais longe. In: Revista Exame, edição 938, ano 43, n 4 , p.100-102, 11/03/2009, p.100-102

BACCEGA, Maria Aparecida (org). Gestão de Processos Comunicacionais. São Paulo: Atlas, 2002.

BECKER, Maria Lúcia. A periferia na cibercultura: técnica, política e exercício da cidadania nos bairros de Curitiba e São Paulo. Tese de Dourado em Comunicação. São Paulo: USP, 2005.

BRAGA, José Luiz; CALAZANS, Regina. Comunicação \& Educação: questões delicadas na interface. São Paulo: Hacker, 2001.

BRITO, Gláucia da Silva; PURIFICAÇÃO, Ivonélia da. Educação, Professor e Novas Tecnologias. 2.ed. revisada e ampliada.Curitiba: Editora Ibepex, 2008.

BRITTOS, Valério Cruz; BOLAÑO, César Ricardo Siqueira. (orgs.) Rede Globo: 40 anos de poder e hegemonia. São Paulo: Paulus, 2005.

CANCLINI, Nestor García. A globalização imaginada. São Paulo: Iluminuras, 2003.

CAPARELLI, Sérgio. Televisão e Capitalismo no Brasil. Porto Alegre: L\&PM Ed., 1982.

CAPPARELLI, Sérgio; LIMA, Venício A. Comunicação e Televisão: Desafios da pósglobalização. São Paulo: Hacker, 2004.

CASTRO, Cosette. Globo e Educação: um casamento que deu certo. In: BRITTOS, Valério Cruz; BOLAÑO, César Ricardo Siqueira (orgs.) Rede Globo: 40 anos de poder e hegemonia.São Paulo: Paulus, 2005, p. 243-263.

CITELLI, Adilson. Palavras, meios de comunicação e educação. São Paulo: Cortez, 2006. "Comunicação e Educação: aproximações”. In: BACCEGA, Maria Aparecida (org).

Gestão de Processos Comunicacionais. São Paulo: Atlas, p. 101-112, 2002.

2000

Comunicação e Educação: a linguagem em movimento. São Paulo: Editora Senac,

DALLA COSTA, Rosa Maria Cardoso; MACHADO, Rafael Costa; SIQUEIRA, Daniele.

Teoria da Comunicação na América Latina: da herança cultural à construção de uma identidade própria. Curitiba: Editora UFPR, 2006.

DALLA COSTA, Rosa Maria Cardoso; JACQUINOT-DELAUNAY. Actions institutionnelles d'éducation pour les médias au Brésil et en France. In: 8eme Colloque Brésil-France: Etat, Culture et communication, 2006. Grenoble: Editado por Intercom e SFSIC, 2006, V.1, p.1-12.

GONNET, Jacques. Éducation et Médias. 2.ed. Paris: Presses Universitaires de France, 1999 (Colection Que sais-je? 3242). 
L'EDUCATION AUX MEDIAS: Avancées, obstacles, orientations nouvelles depuis Grünwald: vers um changement d'echelle? Actes, synthese et recommandations. Rencontre Internationale organisée par la Commision nationale française pour l'Unesco en cooperation avec l'Unesco et avec le soutien du Ministère de l'Education nationale, et du Conseil de l'Europe. 21-22 juin 2007, Paris, France.

MARTIN-BARBERO, Jesús. Dos meios às mediações: comunicação, cultura e hegemonia. 2. ed. Rio de Janeiro: Editora UFRJ, 2003.

MOEGLIN, Pierre. Outils et Médias éducatifs: une approche communicationnelle. Grenbole: PUG, 2005.

NISKIER, Arnaldo (coord.). Reflexões sobre a Educação Brasileira: o compromisso com a qualidade do ensino. Conselho Federal de Educação, Brasília, 1992.

OLIVEIRA, Eliane Basílio de. Tecnologia e educação: um estudo de caso do projeto digitando o futuro, da rede municipal de ensino de Curitiba. Dissertação de Mestrado em Educação. Curitiba: UFPR, 2001.

ORTIZ, Renato. A moderna tradição brasileira. Cultura brasileira e indústria cultural. São Paulo: Brasiliense, 1988.

PESQUISA. Jovens brasileiros "amam" a tecnologia. Jornal Gazeta do Povo. Curitiba, 5 de agosto de 2007, p. 22.

PINHO, Angela. Tecnologia nas escolas reforça a exclusão digital, aponta estudo. Jornal Folha de S. Paulo. São Paulo, 4 de julho de 2007, p. C6.

SALVADOR, Roberto da Costa. Educação a Distância. in: NISKIER, Arnaldo (coord.). Reflexões sobre a Educação Brasileira: o compromisso com a qualidade do Ensino. Conselho Federal de Educação, Brasilia, 1992, p.224-228.

SANTOS, Edméa Oliveira dos. Novas práticas curriculares na educação a distância. In: Comunicação \& Educação.São Paulo: Editora Salesiana. Ano IX,n ${ }^{\circ} 26$ jan/abril 2003, p.35-42.

SOARES, Ismar de Oliveira. "Metodologias da Educação para Comunicação e Gestão Comunicativa no Brasil e na América Latina". In: BACCEGA, Maria Aparecida (org). Gestão de Processos Comunicacionais. São Paulo: Atlas, 2002, p.113-132.

Lei de Diretrizes e Bases e a Comunicação no Sistema de Ensino. Revista Comunicação \& Educação, São Paulo (8), p. 23-26, jan/abri. 1997.

Comunicação/Educação: A emergência de um novo campo e o perfil de seus profissionais. In: Revista Contato, Brasília, DF, ano 1, nº 2, p. 19-74, jan./mar.1999.

SOUSA, Mauro Wilton de. Novas Linguagens. São Paulo: Editora Salesiana, 2001. (Coleção viva voz).

\section{Sítios consultados:}

http://www.telebrasil.org.br/ead.pdf

http://www.virtual.epm.br/material/tis/enf/apostila.htm

http ://ccuap.incubadora.fapesp.br/portal/coletivo/1-historico-da-ead. 